\title{
Predação de morcegos por Chrotopterus auritus (Peters) (Mammalia, Chiroptera) no pantanal de Mato Grosso do Sul, Brasil
}

\author{
Marcelo Oscar Bordignon
}

Departamento de Ciências do Ambiente, Universidade Federal de Mato Grosso do Sul. Avenida Rio Branco 1270, 79304-020

Corumbá, Mato Grosso do Sul, Brasil. E-mail: batbull@bol.com.br

\begin{abstract}
Bat predation by Chrotopterus auritus (Peters) (Mammalia, Chiroptera) in pantanal of Mato Grosso do Sul, Brazil. The predation of Carollia perspiscillata (Linnaeus, 1758) and Peropterix macrotis (Wagner, 1843) by Chrotopterus auritus (Peters, 1856) was registered in a cave at Urucum's mountains of Corumbá, Mato Grosso do Sul, Brazil. The wing fragments and cranium finded under feces deposites, in replace point of $C$. auritus, were comparated with colection reference material and revealed that $C$. auritus can eat occasionaly other bat species that inhabit in same roost.

KEY WORDS. Bat conservation, habitat use, Phyllostomidae, bat roost.
\end{abstract}

RESUMO. Foi registrada a predação de Carollia perspiscillata (Linnaeus, 1758) e Peropterix macrotis (Wagner, 1843) por Chrotopterus autitus (Peters, 1856) em uma caverna na morraria do Urucum em Corumbá, centro-oeste do Brasil. Os fragmentos de asas e um crânio encontrados sob o local de pouso de $C$. auritus junto às fezes, após comparados com material de coleção, mostraram que este morcego alimenta-se oportunamente de outras espécies de morcegos ocupantes do mesmo abrigo.

PALAVRAS CHAVE. Conservação de morcegos, uso do habitat, Phyllostomidae, abrigo de morcegos.

Os morcegos compreendem um grupo de mamíferos de amplo espectro alimentar, possuindo um sistema de ecolocalização elaborado na maior parte das espécies e a peculiar capacidade de voar, o que faz destes animais excelentes predadores noturnos. Apesar dos hábitos alimentares mais comuns entre os morcegos serem a frugivoria (comum entre os Phyllostomidae) e a insetivoria (encontrada nos Vespertilionidae e Molossidae), dietas carnívoras podem ser encontradas em varias espécies deste grupo de mamíferos, tais como: Vampyrum spectrum (Linnaeus, 1758) (Navarro \& Wilson 1982), Phyllostomus hastatus (Pallas, 1767) (GARDNER 1977), Chrotopterus auritus (Peters, 1856) (Medellin 1989, Bonato et al. 2004), Myotis vivesi Menegaux, 1901 (BLood \& Clark 1998), Nyctalus lasiopterus (Schreber, 1780) (Dondini \& Vergari 2000), Noctilio leporinus (Linnaeus, 1758) (Hood \& Jones 1984, BRооке 1994) e Myotis ricketti Thomas, 1894 (MA et al. 2003). No Brasil, o consumo de espécies de vertebrados na natureza por C. auritus foi relatado por PeracChi \& Albuquerque (1976) os quais registraram a predação sobre aves (Columbiformes) e por SAZIMA (1978), o qual analisou o conteúdo estomacal de três exemplares deste morcego e verificou fragmentos de roedores (Muridae), aves e anuros (Hylidae). Bonato et al. (2004) verificaram que pequenos vertebrados perfazem de 61 a $73 \%$ dos itens consumidos por este morcego. Esta espécie é um importante predador noturno, entretanto é um morcego sensível a alterações em seu habitat, tais como redução de áreas florestadas e depredação de seus locais de abrigo, principalmente cavernas. Devido à crescente alteração ambiental, quer seja pelo ecoturismo mal organizado, ou pela exploração de minérios na região do Urucum, os quais interferem no habitar natural de vários morcegos que usam cavernas como abrigo, tornam-se necessários maiores estudos sobre a biologia de $C$. auritus, os quais poderão servir no futuro, como subsídio para estratégias de preservação da espécie no pantanal de Mato Grosso do Sul.

Durante uma incursão realizada em 13 de maio de 2003, acompanhando a equipe da Agência Estadual de Defesa Sanitária Animal e Vegetal (IAGRO, Mato Grosso do Sul), que tinha por objetivo realizar o controle de morcegos hematófagos em uma mina desativada no maciço do Urucum, foi observado um indivíduo de $C$. auritus, o qual não pôde ser capturado. O local de pouso de $C$. auritus distava cerca de $50 \mathrm{~m}$ da entrada principal da mina. Ao verificar-se as fezes depositadas abaixo de seu local de repouso, foram encontrados três fragmentos de asas de morcegos, predados recentemente (possívelmente na noite anterior), bem como um crânio com dentes na arcada superior. Todo o material coletado foi levado ao laboratório para análise e comparação com material de referência. Com base nos frag- 
mentos das asas e do crânio encontrados no local, foi possível identificar duas espécies de morcegos. Um fragmento da asa (braço e antebraço) de Carollia perspicillata (Linnaeus, 1758) e dois fragmentos da asa e um crânio de Peropteryx macrotis (Wagner, 1843). Ambas as espécies predadas, também foram capturadas no mesmo local de abrigo de $C$. auritus, durante o início da incursão, com o uso de puçás, tendo sido acondicionados posteriormente em sacos de algodão, para identificação em laboratório. Com base em observações feitas no local, foi possível constatar que os indivíduos de $P$. macrotis ocupavam sempre as partes mais próximas à entrada da mina, em grupos de 6 a 12 indivíduos, posicionados sempre junto às paredes e apoiados nos quatro membros locomotores. Os indivíduos de C. perspicillata por sua vez, foram avistados em grupos menores (três a nove indivíduos) localizados em locais mais escuros e profundos da mina, entre 50 e $200 \mathrm{~m}$ da entrada, posicionados junto ao teto, geralmente onde haviam grades metálicas usadas para contenção de desabamentos, sempre pendurados pelos pés.

Apesar de serem relatados muitos itens na dieta de C. auritus, incluindo desde pequenos vertebrados a insetos e ser encontrado ocupando locais de abrigo juntamente com outras espécies de morcegos (MEDELLIN 1989), existem poucos relatos sobre a predação de morcegos por esta espécie na literatura. Apenas a predação sobre um exemplar de Glossophaga soricina (Pallas, 1766) foi registrada por Acosta y LARA (1951), sendo esta em território brasileiro. Desta forma, o presente estudo soma mais duas espécies de morcegos à lista de itens alimentares de $C$. auritus, registrando pela primeira vez a predação sobre C. perspiscilata e $P$. macrotis.

A ausência de registros de mais indivíduos de $C$. auritus no local examinado, pode indicar que se tratava de um animal solitário, o qual estaria isolado de um grupo social. Em Corumbá já foram detectados grupos de C. auritus em várias cavernas (JoÃo OrmaY com. pess.), mas este foi o único caso de um indivíduo solitário. A predação de espécies de morcegos por $C$. auritus, demonstra a versatilidade na dieta deste morcego, o que pode contribuir para a sua ocorrência tanto em locais preservados como alterados pela atividade humana.

\section{AGRADECIMENTOS}

Agradeço à Adriana de Oliveira França e João Ormay pelo auxílio em campo e ao IAGRO, Corumbá, pelo apoio logístico. Aos Drs Adriano L. Peracchi e Fernando C. Passos pelas críticas e sugestões.

\section{REFERÊNCIAS BIBLIOGRÁFICAS}

Acosta y LaRA, E.F. 1951. Notas ecológicas sobre algunos quirópteros del Brasil. Comunicaciones Zoologicas del Museo de Montevideo, Montevideo, 3: 1-2.

Blood, B.R. \& M.K. Clark. 1998. Myotis vivesi. Mammalian Species, Washington, 588: 1-5.

Bonato, V.; K.G. Facure \& W. Uieda. 2004. Food Habits of Bats of Subfamily Vampyrinae in Brazil. Journal of Mammalogy, Lawrence, 85 (4): 708-713.

Brooke, A.P. 1994. Diet of the fishing bat, Noctilio leporinus (Chiroptera: Noctilionidae). Journal of Mammalogy, Lawrence, 75 (1): 212-218.

Dondini, G. \& S. Vergari. 2000. Carnivory in the greater noctule bat (Nyctalus lasiopterus) in Italy. Journal of Zoology, London, 252: 233-236.

GARDNER, A.L. 1977. Feeding habits, p. 307-309. In: R.J. BAKER; J.K. Jones Jr. \& D.C. CARTer (Eds). Biology of bats of the New World family Phyllostomidae Par II. Special Publications of The Museum Texas Tech University, Austin, 13: 1-364.

Hood, C.S. \& J.K. Jones JR. 1984. Noctilio leporinus. Mammalian Species, Washington, 216: 1-7.

Ma, J.; G. Jones; S. Zhang; J. Shen; W. Metzner; L. Zhang \& B. LiANG. 2003. Dietary analysis confirms that Rickett's bigfooted bat (Myotis ricketti) is a piscivore. Journal of Zoology, London, 261: 245-248.

Medellin, R.A. 1989. Chrotopterus auritus. Mammalian Species, Washington, 343: 1-5.

NAVARRo, D.L. \& D.E. Wilson. 1982. Vampyrum spectrum. Mammalian Species, Washington, 184: 1-4.

Peracchi, A.L. \& S.T. Albuquerque. 1976. Sobre os hábitos alimentares de Chrotopterus auritus australis Thomas, 1905 (Mammalia, Chiroptera, Phyllostomidae). Revista Brasileira de Biologia, Rio de Janeiro, 36: 179-184.

SAzIMA, I. 1978. Vertebrates as food items of the woolly false vampire, Chrotopterus auritus. Journal of Mammalogy, Lawrence, 59: 617-618.

Recebido em 06.IV.2005; aceito em 22.XI.2005. 